\title{
Gear Ratios Strategy of PROTON Waja CNG-DI Vehicle for Improved Performance
}

\author{
B. B. Sahari (Coresponding Author) \\ Institute of Advanced Technology \\ Universiti Putra Malaysia \\ 43400 UPM Serdang, Malaysia \\ Tel: 60-3-8948-7533Ｅ-mail: barkawi@eng.upm.edu.my \\ Hamzah Adlan, \\ Perusahaan Otomobil Nasional Berhad (Proton) \\ P.O. Box 7100, 40918 Shah Alam, Selangor, Malaysia \\ S. V. Wong \\ Department of Mechanical and Manufacturing Engineering \\ Universiti Putra Malaysia \\ 43400 UPM Serdang, Malaysia
}

Tel: 60-3-8948-7533 E-mail: wongsv@eng.upm.edu.my

\author{
A. M. Hamouda \\ Mechanical and Industrial Engineering Department \\ College of Engineering, Qatar University \\ P.O. Box 2713 -DOHA
}

Tel: 97-4-483-5125 E-mail: hamouda@qu.edu.qa

\begin{abstract}
A $1597 \mathrm{cc}$ gasoline CamPro engine was modified to adapt a Direct Injection (DI) technology that uses Compressed Natural Gas (CNG) as a fuel to form Compressed Natural Gas Direct Injection (CNGDI) engine. The modification includes increasing the compression ratio, redesigning the piston crown and cylinder head and a new engine control systems. These changes resulted in engine performance characteristics which is very different from its gasoline origin. This CNGDI engine is to be used with PROTON Waja vehicle body. Due to this change in the characteristics, the transmission systems utilizing an existing gear ratio combination, appears to be unsuitable, particularly for use in automatic transmission. Therefore, new gearbox with appropriate transmission matching needs to be developed. A computer based algorithm was developed for the purpose of predicting the PROTON Waja's vehicle dynamic performance when CNGDI engine is used. The parameters being considered are maximum speed, acceleration, and elapsed time and these were optimized depending on the engine characteristics such as power, torque, gear ratios, and vehicle design parameters. The results recommended that the gear ratios of 3.58, 1.95, 1.34, 0.98, 0.8 and 4.33 for first, second, third, fourth, fifth and Final Drive (FD) respectively were the most suitable.
\end{abstract}

Keywords: Gear Ratio, Compressed Natural Gas Vehicle, Transmission matching, Vehicle performance 


\section{Introduction}

Natural Gas is cheap and abundant source of energy and suitable for automotive use. However, not many vehicles were designed specially to cater for natural gas. Most natural gas vehicles are converted from gasoline or diesel engine by fitting natural gas equipment such as gas tank and regulators (Das, A. and Watson, H. C., 1997). These vehicles are actually "gasoline or diesel vehicle runs on natural gas". Therefore, they are not dedicated to run on natural gas. Natural Gas can be used as a vehicle fuel in two forms; Compressed Natural Gas (CNG) and Liquefied Natural Gas (LNG). CNG is pressurized gas that is stored in cylindrical tank at pressure up to 250 bar (or 3600 psi) whereas LNG is cooled to a temperature of about $-167^{\circ} \mathrm{C}\left(-260^{\circ} \mathrm{F}\right)$ at atmospheric pressure where it turned into liquid and stored in cylindrical container. $\mathrm{CNG}$ is increasingly seen as effective alternative to petrol or diesel fuel in many internal combustion engines (Rousseau, S. Lemoult, B. Tazerout, M., 1999). One of the major benefits of CNG as an engine fuel is that the exhaust emission can be reduced compared to petrol or diesel. NGV has less emission level as set out by the EURO 3 and EURO 4 requirements. Table 1 shows the results of test on two types of fuel compared to the standards requirement (Middleton, A., Neumann, B., 2005). It can be seen that NGV comply all the requirements of the standards. Hence, natural gas vehicle are becoming important and acceptable.

The main disadvantage of standard petrol engine converted to natural gas is the low power output (Rousseau, S. Lemoult, B. Tazerout, M., 1999). Petrol engine combustion chamber was designed to cater for 9:1 to 10:1 compression ratio while CNG prefer ratios of around 14:1 to $18: 1$ to provide same performance as the equivalent capacity of petrol engine. Hence major modification on petrol engine components needs to be done before it can be used to run on CNG. The major modification may include cylinder head redesign, cam shaft or even cam timing adjustment, revision on cooling and lubrication, and inlet and exhaust tuning. Engine Management System (EMS) re-mapping has to be reconsidered to optimize the performance.

In the present work, a new direct injection common fuel rail technology was developed that will inject fuel at 20 bar pressure to the newly designed combustion chamber to achieve stoichiometric burn engine. Compression ratio used was in the range 13:1 to 15:1. It was designed to create high tumble inlet configuration that resulted in high flame speed and combustion rate with smaller minimum advance for best torque (MBT) spark ignition. This new configuration generates different Torque-speed and Power-speed characteristics. Because of this, new transmission systems need to be developed to cater for this change in torque and power characteristics. There are a number of transmission systems being researched on, and this include gear drives (Litvin, F.L., et. al., 2001), (Keiji Nemoto, Toshiharu Kumagai, Tasushi Ohnuma, 2002), continuous variable transmission systems (Mucino, V.H. et. al., 2001), (Jungmin Seo, Seung Jong Yi, 2005), hydro-mechanical (Dukhwan Sung, Sungho Hwang, Hyunsoo Kim, 2005), and gears with synchronizer (Keiji Nemoto, et. al. 2002). Different techniques were also being used in their analysis which includes simulation and modeling (Kim, J., et. al. 2005), (Jo, H.S., et. al., 2000, Bartlett, H., Whalley, R., 1998). Hence, transmission system is important in improving the vehicle performance. For the present work on CNGDI engine, new gear ratios are needed especially for automatic transmission systems. The objective of the present work was to predict the performance of PROTON Waja vehicle, as shown in Figure 1(a), when fitted with Direct Injection engine using Compressed Natural Gas as a fuel, as shown in Figure 1(b), via selection of different gear ratio and final drive. The running conditions such as 0-400 meter traveled time, $0-100 \mathrm{~km} / \mathrm{h}$ acceleration time, and gear shifting point were used as performance criteria for different ratios. Computer algorithms have been developed specifically to predict the performances of the vehicle. With these algorithms, vehicle parameters such as coefficient of drag, coefficient of rolling resistance, tire rolling radius and effective mass were optimized.

\section{Theoretical background}

The power from the engine, $P$, was calculated using the following equation:-

$P=\frac{P_{e f f} V_{d} N_{r}}{1000 n}$

Where $P_{\text {eff }}$ is the brake mean effective pressure, bmep, in $\mathrm{kPa}, V_{d}$ is the cylinder volume, $N_{r}$ is the speed in revolutions per second and $\mathrm{n}$ is the revolutions per cycle.

The Traction Effort $\left(T_{E}\right)$ is the force developed at the driving wheels and is the sum of wind resistance force, rolling resistance and gravitational resistance. Taking into account all these components of forces, the expression for $T_{E}$ was defined by:

$T_{E}=K_{1} W \cos \phi+K_{2} V^{2} A+W \sin \phi$

Where $K_{1}$ is the road surface co-efficient, $K_{2}$ is the coefficient of vehicle frontal area, $V$ is the vehicle speed in $\mathrm{km} / \mathrm{h}, W$ is the vehicle weight, $A$ is the vehicle frontal area and $\Phi$ is the road gradient.

The selection of engine speed to the vehicle speed ratio, $N_{v}$, is given as:

$N_{V}=\frac{N_{e}}{V}=\frac{2660 R_{a} R_{t}}{R_{r}}$ 
Where $N_{e}$ is the engine speed in rpm, $R_{a}$ is the axle ratio, $R_{t}$ is the transmission ratio and $R_{r}$ is the average effective rolling tire radius.

In most design, the first gear is always chosen to be the lowest denoted by $R_{T 1}$. The highest gear ratio $R_{T N}$ is usually selected by the designer. Hence, when $R_{T 1}$ and $R_{T N}$ have been defined, the numbers of forward gear, $N$ and the intermediate gear ratios factor $K$ are determined by using the following expression:

$K=\left(\frac{R_{T N}}{R_{T 1}}\right)^{1^{\prime}(N-1)}$

Having determined the value of $K$, the intermediate gear ratio (that is $i^{\text {th }}$ gear ratio), $R_{T g}$, is then determined from the general geometric progression expression given by:-

$R_{T g}=K R_{T g-1}$

Where $R_{T g-1}$ is the $(i-1)^{\text {th }}$ gear ratio.

Equations (1) to (5) were necessary to determine the appropriate gear ratios for the optimum vehicle driving performance. At each stage of the calculation, the power at the wheel has to be matched against the power and torque characteristics of the engine. Although CNGDI engine is derived from the gasoline engine, its characteristics differ from the gasoline base. Therefore, there is a need to reassess and determine the appropriate gear ratios.

\section{Methodology}

A computer algorithm was developed based on Equations (1) to (5) and was capable of calculating gear ratio and final drive for pre-determined parameters. This enables the optimized parameters for different transmission setup condition to be obtained. Table 2 shows the sets of transmission ratio that were calculated and will be used in the present study. The ratios were then obtained from the algorithms developed for a number of cases and for different conditions. Two different sets of gear ratio together with the three different set of final drive ratio at fixed vehicle parameters were used. Two sets of gear ratio are being used; namely Set 1, Set 2 and Set 3. Set 1 is the current production in-vehicle ratio and is used as a benchmark gear set. Set 2 and Set 3 are the new sets to be studied. Design parameters used are coefficient of drag, coefficient of rolling, rolling radius, effective mass and engine displacement. The weight of the vehicle was set to be a total of $1415 \mathrm{~kg}$. The vehicle weight includes 1 driver and 2 adult passengers. The evaluations on the vehicle performance were based on the time taken to cover $0-100 \mathrm{~km} / \mathrm{h}$ and time taken to cover $0-400$ meter, $0-1000$ meter traveled. In addition to that, other parameters such as maximum speed, vehicle speed, $N_{V}$ ratio, engine power and total resistance could be extracted for the different running condition.

\section{Results and Discussions}

The variation of power and torque with engine speed for the CNG-DI CamPro engine is shown in Figure 2. It is based on the results of tests on Single Cylinder Research Engine. From Figure 2, it can be seen that the maximum torque achievable is $148 \mathrm{Nm}$ at 4000 revolution per minute (rpm) whereas the power is $85 \mathrm{~kW}$ at $6000 \mathrm{rpm}$. The minimum torque at idling speed is $108 \mathrm{Nm}$, which is similar to a gasoline CamPro engine. The torque curve is not flat without torque dip. This torque profile is common for engine equipped with Dual Overhead Camshaft (DOHC) without variable valve timing (VVT). From $4000 \mathrm{rpm}$ to $6000 \mathrm{rpm}$, the torque is relatively stable until it reaches $7000 \mathrm{rpm}$ which the electronic engine cut off switch is activated. It is seen that the torque decreases from $142 \mathrm{Nm}$ to $125 \mathrm{Nm}$ from 6000 $\mathrm{rpm}$ to $7000 \mathrm{rpm}$ which indicated a decrease in induction air volumetric efficiency. As for the power curve, Figure 2 indicated that the power increases almost linearly until $5000 \mathrm{rpm}$ and after that the curves started to flatten and reaches its peak at about $6500 \mathrm{rpm}$. Theoretically, the maximum power output of $85 \mathrm{~kW}$ was achieved which is equivalent to a specific power output of $53.1 \mathrm{~kW}$ per liter.

The variation of flywheel power with vehicle speeds at different road gradients is shown in Figure 3 for PROTON Waja car equipped with CNG-DI CamPro engine. It can be seen that, at maximum power of $85 \mathrm{~kW}$, on a flat terrain of (gradient $=0 \%$ ), the car is capable to reach a top speed of $164 \mathrm{~km} / \mathrm{h}$. However, the top speed reached is reduced to $160 \mathrm{~km} / \mathrm{h}$ as the slope is increased to 7 percent. A further drop to $149 \mathrm{~km} / \mathrm{h}$ is apparent as the car climbs a 25 percent gradient terrain. This is considered to be an acceptable achievement since the speed limit in most expressways is 110 $\mathrm{km} / \mathrm{h}$.

The relationship between flywheel power and vehicle speeds depends on the gear ratio used and are shown in Figure 4 for Set 1, Figure 5 for Set 2 and Figure 6 for Set 3. From Figure 4, it can be seen that the intercept point from the first to the second gear occurred at $51 \mathrm{~km} / \mathrm{h}$. The intercept for second to third gear occurred at $92 \mathrm{~km} / \mathrm{h}$, third to fourth at 130 $\mathrm{km} / \mathrm{h}$, fourth to fifth at $170 \mathrm{~km} / \mathrm{h}$ before reaching the top speed of $190 \mathrm{~km} / \mathrm{h}$. These intercept points indicated the maximum speed for gear change for optimum performance, particularly for automatic transmission. However, for manual transmission, gear change could be carried out at a lower than the speeds at intercept. Hence, the intercept provide useful guides for gear change strategy. For Set 2, the relation between the power and vehicle speeds is shown in Figure 5. The gear change intercept are $48 \mathrm{~km} / \mathrm{h}, 82 \mathrm{~km} / \mathrm{h}, 120 \mathrm{~km} / \mathrm{h}$ and $160 \mathrm{~km} / \mathrm{h}$ and attained maximum speed of approximately $180 \mathrm{~km} / \mathrm{h}$. These values are slightly different from that of Set 1 . For Set 3, the relation is shown in Figure 
6, and the intercepts occurs at $46 \mathrm{~km} / \mathrm{h}, 66 \mathrm{~km} / \mathrm{h}, 96$ and $140 \mathrm{~km} / \mathrm{h}$ and maximum speed also at $180 \mathrm{~km} / \mathrm{h}$. These values are given in Table 3 for ease of comparison. There are two conclusions that can be drawn from the above results. Firstly, a good driver can achieve the timing 0 to $100 \mathrm{~km} / \mathrm{h}$ closer to the fourth gear. This shows that for Set 3 the car is faster by using a bigger final gear ratio but utilize more fuel because of higher engine rotation being used compared to Set 1 or Set 2. Secondly, one can conclude that the fifth gear is finally utilized before the maximum speed is achieved in zero gradient terrain.

Figure 7 shows the relationship between the speed attained and time taken. This is important as it shows how fast the car sprint from 0 to $100 \mathrm{~km} / \mathrm{h}$. As expected, from the shifting points for three different final gear ratios, it is clear that the bigger the final gear ratio the faster the car sprints to the $100 \mathrm{~km} / \mathrm{h}$ mark. It can be seen from the curve that Set 2 is better from starting from the beginning of acceleration. Thus to achieve performance and hence fuel savings and emission control with natural gas, Set 2 is recommended to be used.

Vehicle performance for all Sets 1, 2 and 3 at different performance evaluation is shown in Figure 8. For 0 to $1000 \mathrm{~m}$, Set 1 achieved $33 \mathrm{sec}$ to complete while Set 2 achieved $32.9 \mathrm{sec}$ and Set 3 achieved $33.2 \mathrm{sec}$. Set 2 has the fastest completion time because of bigger final drive ratio and suitable gear combination compared to Set 1 and Set 3 . This is due to more torque to be delivered to the driveline as a result of faster acceleration time. The setback for the bigger final drive ratio is higher engine revolution that will give an impact on fuel consumption. Performance and fuel consumption have to be balanced depending on where (which country) to market the car, topography, demography and fuel price. Set 2 also has the best 0 to 400 meter completion time and 0 to $100 \mathrm{~km} / \mathrm{h}$ sprint time.

\section{Conclusion}

From the results obtained, it can be concluded that Set 2 gear ratio combination for $1^{\text {st }}, 2^{\text {nd }}, 3^{\text {rd }}, 4^{\text {th }}, 5^{\text {th }}$, and Final Drive of $3.583,1.947,1.343,0.976,0.804$ and 4.334 respectively was found to be suitable for best performance output of PROTON Waja CNG-DI vehicle in terms of gear shifting point, acceleration and drivability. Although the overall performance difference is small, Set 2 has shown a driver friendly set of gear combination.

\section{References}

Bartlett, H., Whalley, R., (1998). "Power Transmission Systems Modeling”, Proc IMechE, Part D, Journal of Automobile Engineering, Vol. 212, No. 6, pp 497-505.

Das, A., Watson, H. C., (1997). "Development Of Natural Gas Spark Ignition Engine For Optimum Performance", Proc IMechE, Part D, Journal of Automobile Engineering, Vol. 211, No. 5, pp 361-378.

Dukhwan Sung, Sungho Hwang, Hyunsoo Kim, (2005). "Design Of Hydromechanical Transmission Using Network Analysis”, Proc IMechE, Part D, Journal of Automobile Engineering, Vol. 219, No. 1, pp 53-63.

Jo, H.S., Jang, W.J., Lim, W.S., Lee, J.M., Park, Y.I., (2000). "Development Of A General Purpose Program Based On The Concept of Subsystem Assembly For The Analysis of Dynamic Characteristics Of Power Transmission System", Proc IMechE, Part D, Journal of Automobile Engineering, Vol. 214, No. 5, pp 545-560.

Jungmin Seo, Seung Jong Yi, (2005). "Design Of Automatic Transmission System Having Arbritary Power Flow Using The Automatic Power Flow Generation Algorithm", Proc IMechE, Part D, Journal of Automobile Engineering, Vol. 219, No. 9, pp 1085-1097.

Keiji Nemoto, Toshiharu Kumagai, Tasushi Ohnuma, (2002). "Development Of A New Manual Transmission”, JSAE Review 23, pp 513-518

Kenichi Satoh, Masanori Shinitani, Setsukazu Akai, Kazuyoshi Hiraiwa , (2003). "Development Of A New Synchronizer With The Lever Mechanism", JSAE Review 24, pp 93-97

Kim, J., Park, S., Seok, C., Song, H., Sung, D., Lim, C., Kim, J., Kim, H., (2005). "Simulation Of Shift Force For A Manual Transmission", Proc IMechE, Part D, Journal of Automobile Engineering, Vol. 217, No. 7, pp 573-581.

Litvin, F.L., Fuentes, A., Demenego, A., Vecchiato, D., Fan, Q., (2001). "New Developments In The Design And Generation Of Gear Drives”, Proc IMechE, Part D, Journal of Automobile Engineering, Vol. 215, No. 7, pp 747-757.

Middleton, A., Neumann, B., (2005). "CNG Engine Technology For Fleets - Performance, Emissions And Cost Effectiveness", Paper 9, Proceedings, ANGVA 2005, ${ }^{\text {st }}$ Conference \& Exhibition, Kuala Lumpur.

Mucino, V.H. Lu, Z., Smith, E., Kimcikiewicz, M., Cowan, B., (2001). "Design Of Continuously Variable Power Split Transmission Systems For Automotive Applications", Proc IMechE, Part D, Journal of Automobile Engineering, Vol. 215, No. 4, pp 469-478.

Rousseau, S. Lemoult, B. Tazerout, M., (1999). "Combustion Characterization Of Natural Gas In Lean Burn Spark Ignition Engine", Proc IMechE, Part D, Journal of Automobile Engineering, Vol. 213, No. 5, pp 481-489. 
Table 1. Comparisons of emission level for different standards. (Middleton, A., Neumann, B., 2005). (Units: grams/kilowatt hour)

\begin{tabular}{|l|c|c|c|c|c|}
\hline & $\mathrm{CO}$ & $\mathrm{NMHC}$ & $\mathrm{CH} 4$ & $\mathrm{NO}_{\mathrm{X}}$ & $\mathrm{PM}$ \\
\hline EURO 3 limit & 5.45 & 0.78 & 1.6 & 5.0 & 0.16 \\
\hline EURO 4.1 limit & 4.0 & 0.55 & 1.1 & 3.5 & 0.03 \\
\hline $\begin{array}{l}\text { NGV test results G20 } \\
\text { gas }\end{array}$ & 0.131 & 0.011 & 0.156 & 3.09 & 0.006 \\
\hline $\begin{array}{l}\text { NGV test results G25 } \\
\text { gas }\end{array}$ & 0.134 & 0.020 & 0.459 & 2.88 & 0.007 \\
\hline
\end{tabular}

Table 2. Simulation transmission options

\begin{tabular}{|c|c|c|c|c|c|c|}
\hline & \multicolumn{7}{|c|}{ Gear ratios } \\
\hline Combination & First & Second & Third & Fourth & Fifth & Final Drive \\
\hline Set 1 & 3.583 & 1.947 & 1.343 & 0.976 & 0.804 & 4.052 \\
\hline Set 2 & 3.583 & 1.947 & 1.343 & 0.976 & 0.804 & 4.334 \\
\hline Set 3 & 3.545 & 2.447 & 1.688 & 1.165 & 0.804 & 4.410 \\
\hline
\end{tabular}

Table 3. Intercept speeds for gear change.

\begin{tabular}{|c|c|c|c|c|c|}
\hline \multirow{2}{*}{ Combination } & \multicolumn{5}{|c|}{ Speeds in km/h } \\
\cline { 2 - 6 } & First to second & $\begin{array}{c}\text { Second to } \\
\text { third }\end{array}$ & $\begin{array}{c}\text { Third to } \\
\text { fourth }\end{array}$ & $\begin{array}{c}\text { Fourth to } \\
\text { fifth }\end{array}$ & $\begin{array}{c}\text { Maximum } \\
\text { speed }\end{array}$ \\
\hline Set 1 & 51 & 92 & 130 & 170 & 190 \\
\hline Set 2 & 48 & 82 & 120 & 160 & 180 \\
\hline Set 3 & 46 & 66 & 96 & 140 & 180 \\
\hline
\end{tabular}

\section{Table Caption}

Table 1. Comparison of emission level against standard (Middleton, A., Neumann, B., 2005). (Units: grams/kilowatt hour)

Table 2. Simulation transmission option

Table 3. Intercept speeds for gear change



Figure 1. (a) PROTON Waja and (b) CamPro CNG-DI engine 




Figure 2. CNGDI Engine performance



Figure 3. Power versus vehicle speed at different road gradient 




Figure 4. Power versus speed for Set 1

\section{SPEED VS POWER}



Figure 5. Power versus vehicle speed for Set 2 


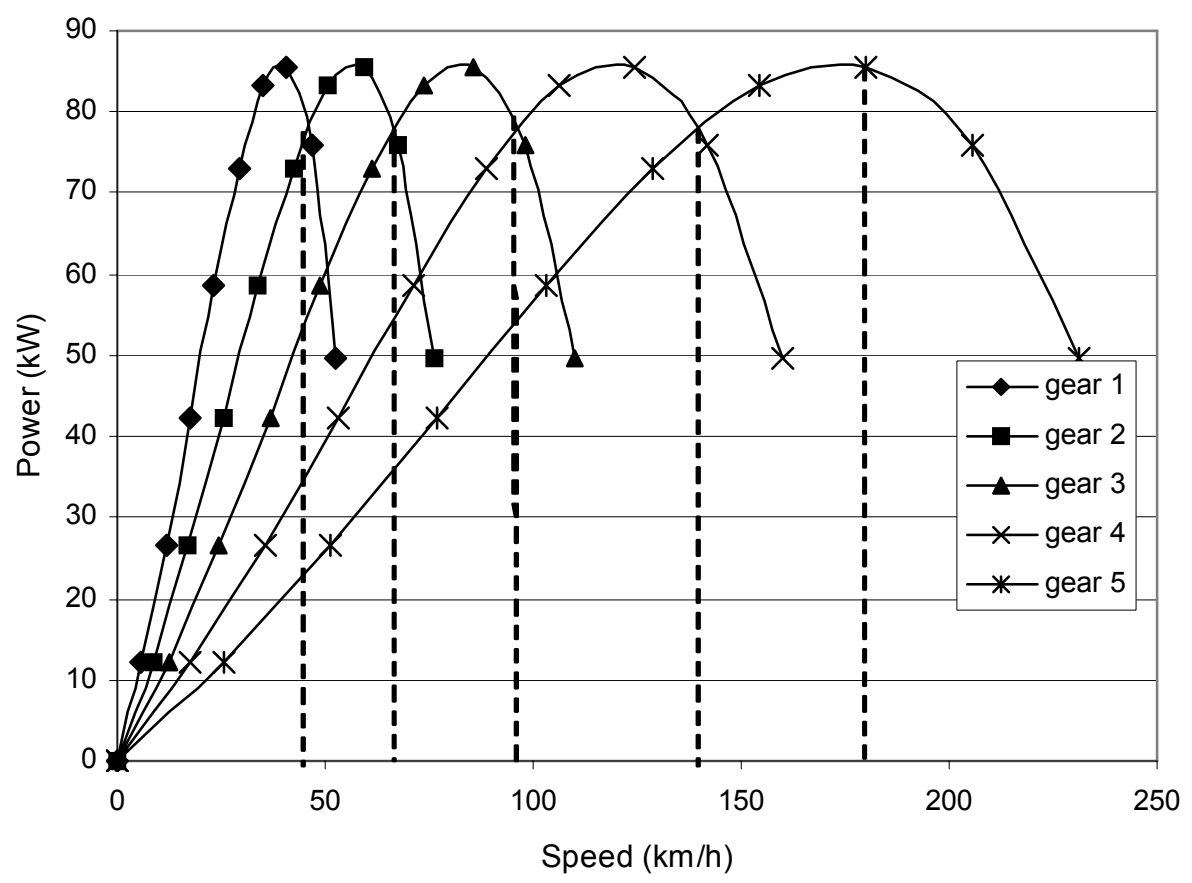

Figure 6. Power versus vehicle speed for Set 3

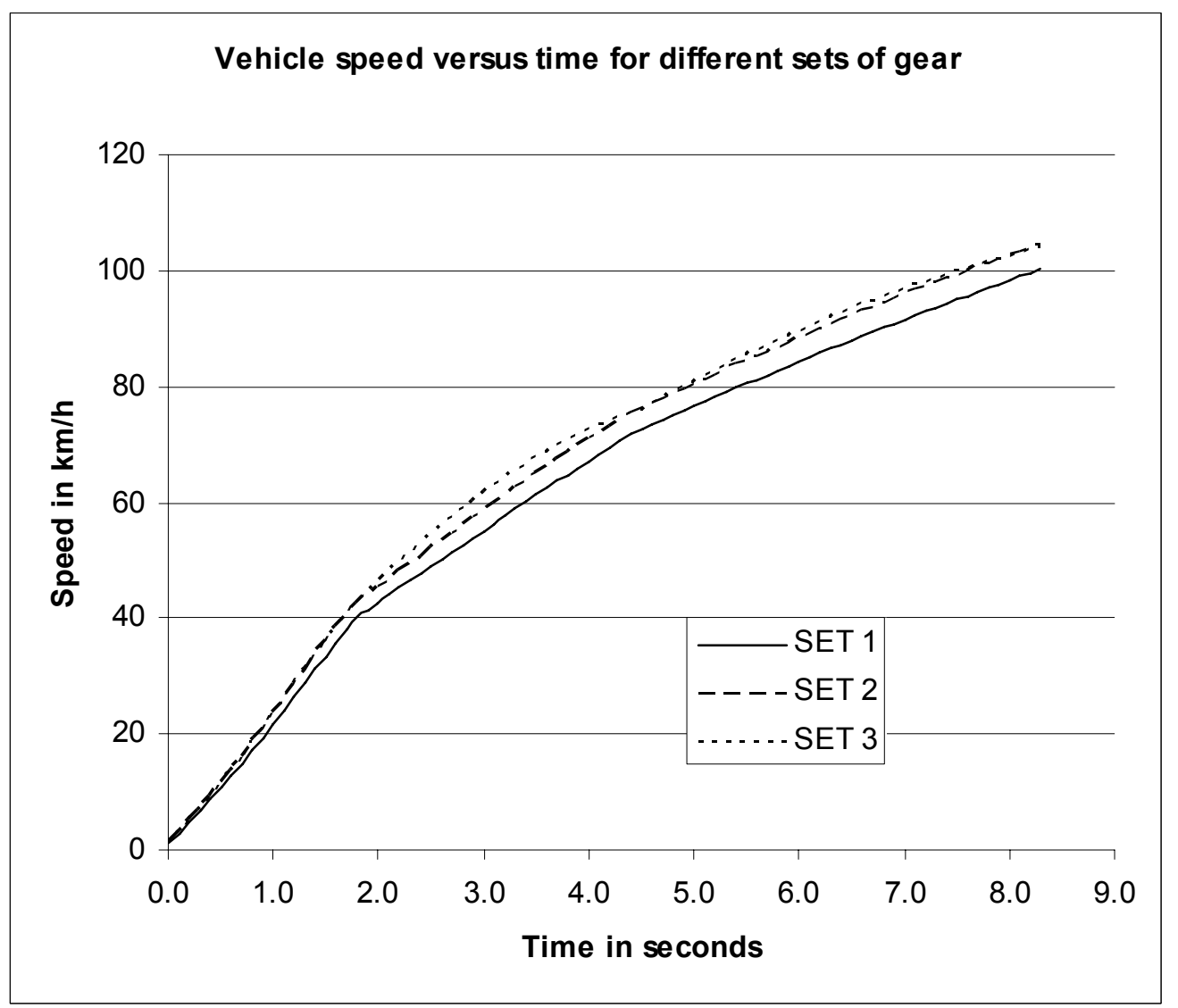

Figure 7. Speed versus time for gear set 1, 2 and 3 




Figure 8. Vehicle performance (in sec) for different sets of gears

\section{Figure Caption}

Figure 1. (a) PROTON Waja and (b) CamPro CNG-DI engine

Figure 2. CNGDI Engine performance

Figure 3. Power versus vehicle speed at different road gradient

Figure 4. Power versus speed for Set 1

Figure 5. Power versus vehicle speed for Set 2

Figure 6. Power versus vehicle speed for Set 3 